\title{
Visão retrospectiva em fibras alimentares com ênfase em beta- glucanas no tratamento do diabetes
}

\author{
Giane Sprada Mira $^{1 *}$, Hans Graf ${ }^{1}$, Lys Mary Bileski Cândido ${ }^{2}$ \\ ${ }^{1}$ Departamento de Clínica Médica, Universidade Federal do Paraná, ${ }^{2}$ Departamento de Nutrição e Programa de \\ Pós-Graduação em Ciências Farmacêuticas, Universidade Federal do Paraná
}

\begin{abstract}
Fibra alimentar refere-se aos componentes de plantas ou carboidratos análogos que são resistentes à digestão e absorção no intestino delgado humano. A American Dietetic Association recomenda ingestão de $20-35 \mathrm{~g}$ de fibras ao dia. Evidências sugerem que uma dieta rica em fibras traz benefícios à manutenção da saúde, redução de risco e tratamento de doenças crônicas como a obesidade, doenças cardiovasculares, diverticulite e diabetes. As fibras são classificadas de acordo com a sua solubilidade em solúveis e insolúveis, com efeitos fisiológicos distintos. As insolúveis são responsáveis pelo aumento do bolo fecal e diminuição do tempo de trânsito intestinal. As solúveis retardam o esvaziamento gástrico e a absorção de glicose diminuindo a glicemia pós-prandial e reduzem o colesterol sérico devido à sua característica física de conferir viscosidade ao conteúdo luminal. As beta-glucanas são fibras altamente viscosas e seu consumo está relacionado à atenuação da resposta glicêmica e insulínica pós-prandial. A beta-glucana tem efeito sobre a degradação do amido e sobre o carboidrato disponível e conseqüentemente, sobre o índice glicêmico dos alimentos ingeridos. Recomenda-se sua ingestão com o objetivo de modular a glicemia e a necessidade de insulina, no tratamento da obesidade, doenças cardiovasculares e do diabetes. Este trabalho visa fornecer uma visão geral sobre beta-glucanas no tratamento do diabetes.
\end{abstract}

Unitermos: Fibras alimentares. Beta-glucanas. Diabetes/tratamento. Glicemia.

Dietary fibers are defined as the component of the plants or analog carbohydrates that are resistant to digestion and absorption in the human small bowel. The America Dietetic Association recommends an ingestion of 20-30g of fiber per day. Evidences suggest that a diet rich in fibers brings benefits to health maintenance, by reducing the risk and the time of treatment of chronic diseases such as obesity, cardiovascular diseases, diverticulitis and diabetes. Fibers are classified as a soluble and insoluble with distinct physiological effects. Ingestion of insoluble fibers increases the fecal bolus and reduces the transit time of food through the bowel. Soluble fibers delay gastric emptying and glucose absorption reducing the post prandial glycemia and reduce blood cholesterol levels due to a physic characteristic that confers viscosity to the luminal content. Beta-glucans are highly viscous and their consumption has been related to the attenuation of post-prandial glycemic and insulin response. Dietary beta-glucans have impact on starch degradation and carbohydrates availability and consequently at the glycemic index of the ingested food. Consumption of beta-glucans is recommended aiming to modulate the glycemia and the insulin needs, to manage the obesity, cardiovascular diseases and diabetes. This paper brings information about dietary fibers and the use of beta-glucans on the treatment of diabetes.

Uniterms: Dietary fibers. Beta-glucans. Diabetes/treatment. Glycemia.

\footnotetext{
*Correspondência:G. S. Mira. Departamento de Nutrição, Universidade Federal do Paraná, Rua Lothario Meissner, 632 - Jardim Botânico - 80210-170

- Curitiba - PR, Brasil. E-mail: gianemira@ufpr.br
} 


\section{INTRODUÇÃO}

\section{Características gerais das fibras}

Fibra Alimentar é a porção de plantas ou carboidratos análogos que são resistentes à digestão e absorção no intestino delgado de humanos, com fermentação completa ou parcial no intestino grosso. O termo fibra alimentar inclui polissacarídeos, lignina, oligossacarídeos e substâncias associadas de plantas promovendo benefícios fisiológicos (American Dietetic Association - ADA, 2002). Esta definição foi elaborada pela American Association of Cereal Chemists em 1999, após debates subsidiados por informações colhidas de indústrias, academias e órgãos governamentais ao redor do mundo (Catalani et al., 2003). Entre as propriedades fisiológicas atribuídas às fibras estão: redução do colesterol sérico, modulação da glicemia e propriedades laxativas (Brennan, 2005).

De acordo com a solubilidade em água a fibra alimentar é classificada em 2 grupos distintos: fibras solúveis e fibras insolúveis e sua atividade fisiológica é determinada com base na solubilidade (Catalani et al., 2003; Brennan, 2005).

A National Academy of Science, em 2003, propôs duas novas subdivisões que são: 'fibra alimentar' - intrínseca e intacta das plantas e 'fibra adicionada' - carboidratos não digeríveis que foram isolados, fabricados ou que são sintéticos (Food and Nutrition Board, 2001). Porém esta definição não é muito utilizada, prevalecendo as categorias solúveis e insolúveis.

A Fibra Alimentar Total (FAT) está presente nas paredes das células vegetais, principalmente na parte periférica ou casca, conferindo firmeza e estrutura ao alimento vegetal. É composta principalmente por polissacarídeos complexos associados a polifenóis, a proteínas e fitatos, e sua concentração varia com a espécie, variedade e tipo de armazenamento do vegetal (Araújo, Araújo, 1998).

O principal local de digestão e absorção de nutrientes é o intestino delgado, onde ocorre hidrólise de polímeros na primeira parte de duodeno (Johnson, Southgate, 1994). Assim a manipulação dietética que provoca uma alteração neste ambiente, afetará a digestibilidade dos alimentos consumidos, assim como da composição das fezes. As fibras alimentares têm como características comuns não serem digeridas no intestino delgado e serem fermentadas no intestino grosso. As propriedades fisicoquímicas, enquanto passam pelo trato digestório, é que afetam o metabolismo de certos nutrientes e a regulação de algumas doenças. Estas propriedades fisicoquímicas seriam a conformação das cadeias polissacarídicas e a maneira como estas interagem com outros componentes da dieta (Brennan, 2005).
No Brasil o consumo de fibras alimentares tem diminuído nas últimas décadas em virtude da mudança do perfil sócio econômico da população, o que mudou o estilo de vida e os hábitos alimentares dos indivíduos. Um estudo concluiu que a ingestão de fibras alimentares através de alimentos como feijão, pão e arroz, diminuiu entre os anos 70 e 90, por ocasião da substituição de tais alimentos por outros, ricos em gorduras e industrializados (Catalani et al., 2003).

Este trabalho consiste em uma revisão do conhecimento disponível na literatura científica sobre fibras alimentares, com ênfase em beta-glucanas; e tem como objetivo discutir a influência destas fibras na saúde do indivíduo. Utilizaram-se as bases Medline, Lilacs e Scielo, buscando-se publicações disponíveis entre 1970 e 2007, adotando-se os termos de base fibra, fibra alimentar, fibra solúvel, fibra insolúvel, beta-glucana e índice glicêmico. Foram incluídos textos em inglês, português e espanhol e excluídos os trabalhos publicados em outras línguas ou disponíveis somente no formato abstract.

\section{Fibras alimentares e manutenção da saúde}

As fibras alimentares têm demonstrado benefícios à manutenção da saúde e prevenção de doenças. Segundo posicionamento da American Dietetic Association de 2002, o consumo de fibras alimentares totais deve ser de 20 a $35 \mathrm{~g}$ por dia ou 10 a $14 \mathrm{~g}$ de fibras $/ 1000 \mathrm{kcal}$ (American Dietetic Association - ADA, 2002).

São vários os benefícios atribuídos ao consumo adequado de fibras alimentares, verificados através de estudos clínicos e epidemiológicos, como por exemplo: diminuição do colesterol; prevenção da constipação; aumento da saciedade; redução do risco de diabetes tipo 2 e doenças cardiovasculares; prevenção e tratamento de diverticuloses e manejo do diabetes tipo 1 (American Dietetic Association - ADA, 2002).

As fibras responsáveis pela diminuição do colesterol são as beta-glucanas presentes no farelo de aveia, cevada e no psyllium, que já foram estudadas e receberam a aprovação da Food and Drug Administration, que autorizou a declaração de alimento benéfico à saúde. Os alimentos que contém pelo menos $0,75 \mathrm{~g}$ de beta-glucanas/porção e $1,7 \mathrm{~g}$ de psillyum/porção podem reduzir o risco de doenças do coração (FDA, 2001).

Um estudo com 68 indivíduos hiperlipidêmicos avaliou a eficácia de uma dieta padrão acrescida de fibras solúveis, na forma de beta-glucanas e psyllium, na redução do colesterol plasmático. Os resultados demonstraram que a dieta enriquecida com fibras solúveis reduziu os níveis de colesterol total $(2,1 \pm 0,7 \% ; p=0,003)$, LDL colesterol 
$(2,4 \pm 1,0 \% ; p=0,015)$ e apolipoproteína $(1,4 \pm 0,8 \% ; p=$ $0,076)$. A redução dos níveis séricos de lipídios diminui os fatores de risco para doenças cardiovasculares. O estudo suporta a declaração de alimento benéfico à saúde, feita pela FDA (Jenkins et al., 2002).

Na prevenção da constipação as fibras agem aumentando o volume das fezes, pela captação de água e pela fermentação parcial das mesmas, normalizando o trânsito intestinal (Kurasawa, Haak, Marlett, 2000) e através da produção de quantidade suficiente de massa fecal no cólon e diminuição da força de contração na propulsão das fezes, havendo uma diminuição dos riscos de diverticulose (American Dietetic Association - ADA, 2002).

Com relação ao aumento da saciedade, as refeições ricas em fibras são processadas mais lentamente do que as isentas de fibras, além disso, apesar de serem de grande volume são de baixa densidade calórica, o que limita a ingestão energética (Rolls et al., 1999).

Evidências experimentais têm demonstrado que a ingestão de fibras solúveis retarda o esvaziamento gástrico e a digestão e diminui a absorção de glicose, beneficiando diretamente a glicemia pós prandial de portadores de diabetes (Chandalia, 2000). Um estudo de coorte demonstrou relação inversamente proporcional entre a ingestão de fibras de cereais e o risco de Diabetes Mellitus tipo 2 em homens (Salmeron et al., 1997). Na mesma linha de pesquisa, anos mais tarde, Giacco et al. (2000) publicaram um estudo onde avaliaram o efeito de uma dieta rica em fibras, através de alimentos naturais, sobre a glicemia e eventos de hipoglicemia em portadores de diabetes tipo 1 . O estudo avaliou 63 indivíduos randomizados que receberam dieta rica ou pobre em fibras (50 e $15 \mathrm{~g}$ de fibras/dia, respectivamente), principalmente solúveis, por 24 semanas; sendo que as porcentagens de carboidratos, proteínas, lipídeos e colesterol eram as mesmas para os dois grupos. Foram avaliados, LDL colesterol, HDL, hemoglobina glicosilada e glicemia pós prandial. Os resultados mostraram que, comparada com a dieta pobre em fibras, a dieta rica em fibras reduziu significativamente a glicemia pós prandial, a hemoglobina glicosilada e o número de episódios de hipoglicemia (Giacco et al., 2000).

\section{Tipos de fibras}

\section{Fibras insolúveis}

Fibras insolúveis não são viscosas, são formadoras de volume fecal, fraca e lentamente fermentáveis no cólon. Agem principalmente no intestino grosso, produzindo fezes macias e acelerando o trânsito colônico (Harber, 1997). As fibras alimentares insolúveis correspondem à celulose, hemicelulose e lignina. A celulose apresenta cadeia não ramificada, com pontes de hidrogênio e conformação molecular cristalina envolvida pela matriz da parede celular, o que lhe confere baixa solubilidade em água. As hemiceluloses se encontram junto à celulose, à lignina e à pectina na parede celular dos vegetais e o grau de solubilidade é dado pela presença de moléculas de xilose. A lignina tem estrutura tridimensional complexa e é hidrofóbica (Food and Nutrition Board, 2001).

As fibras insolúveis contribuem para o aumento do volume fecal por retenção de água, reduzindo o tempo de trânsito intestinal, a absorção de glicose e retardo da hidrólise do amido. São encontradas no farelo de trigo, cereais integrais, raízes e hortaliças (Catalani et al., 2003).

$\mathrm{O}$ farelo de trigo e a celulose presente nos vegetais aumentam o peso fecal úmido sendo particularmente indicados para promover melhora da função intestinal, o que pode explicar seu efeito na absorção diminuída de triacilgliceróis e colesterol (Stark, Mayers, 1995).

\section{Fibras solúveis}

As fibras solúveis têm alta capacidade de retenção de água e possuem a propriedade de formar géis em solução aquosa. Na indústria de alimentos, têm a propriedade de alterar a viscosidade de produtos alimentares e por isso são denominadas gomas ou hidrocolóides (Brennan, 2005). Uma vez no estômago e no intestino delgado, as fibras solúveis aumentam a viscosidade do bolo alimentar, diminuindo a atividade de certas enzimas digestivas, influenciando diretamente na taxa de digestão e absorção de nutrientes (Endress, Fischer, 2001; Cameron-Smith, Collier, O'Dea, 1994). Esta influência está diretamente ligada à moderação da glicemia pós prandial e resposta insulínica, redução do colesterol e regulação do apetite (Davidson et al., 1998; Antilla; Sontag-Strohm; Salovaara, 2004).

As fibras solúveis correspondem às substâncias pécticas, as glucanas, gomas e mucilagens, algumas hemiceluloses e o psyllium.

\section{- Pectina}

A pectina apresenta uma extensa cadeia de moléculas parcialmente esterificadas de ácido galacturônico e metil galacturônico e são solúveis em água. A pectina é uma fibra estrutural encontrada na parede celular e na camada intracelular de vegetais e sua solubilidade está associada ao grau de maturidade do vegetal. Tem alta capacidade de reter água e formar gel, é completamente fermentada no cólon e pode se unir a íons e material orgânico, como a bile (Wursch, Xavier, Sunyer, 1997). Em um estudo de Fietz (1999), avaliou-se o efeito da pectina de alta e baixa metoxilação e da celulose, sobre os níveis de colesterol e triacilgliceróis em ratos hipercolesterolêmicos. Os resul- 
tados demonstraram que no grupo tratado com pectina e celulose, houve uma diminuição do peso com o aumento da ingestão de fibras, e dietas com 10 e $15 \%$ de pectina reduziram os níveis de colesterol, triacilgliceróis e uréia (Fietz, Salgado, 1999). À pectina é atribuído o efeito de retardar o esvaziamento gástrico. Para avaliar esta propriedade, Schwartz et al. (1988) suplementaram uma dieta isocalórica, com baixa concentração de fibras, com pectina da maçã em 12 indivíduos diabéticos tipo 2 . Observaram diminuição de $43 \%$ do tempo de esvaziamento gástrico nos indivíduos tratados com pectina. Além disso, a fibra diminuiu o incremento da área sob a curva de tolerância à glicose (Schwartz et al., 1988). Mais recentemente, Derivi e cols. avaliaram, em ratos Wistar, o efeito de uma ração formulada com berinjela (rica em pectina). Os resultados demonstraram que os ratos diabéticos alimentados com ração à base de casca de berinjela, apresentaram menor área sob a curva de tolerância à glicose que os ratos controle, e concluiu-se que a administração contínua de pectina pode contribuir para o controle da glicose pós prandial (Derivi et al., 2002).

Entretanto, um estudo de intervenção randomizado em humanos, controlado, duplo cego, realizado com 66 indivíduos com metabolismo anormal da glicose, demonstrou outro resultado. Por 12 semanas, os indivíduos consumiram uma bebida enriquecida com pectina e polidextrose em comparação a uma bebida sem fibra (grupo controle). Foi avaliada a glicemia de jejum, pós-prandial e o perfil lipídico. O estudo demonstrou não haver efeito positivo da pectina e polidextrose sobre a glicemia de jejum, glicemia pós prandial e sobre o perfil lipídico em indivíduos com metabolismo anormal da glicose (Schwab et al., 2006). Importante salientar que os estudos acima em ratos e humanos não podem ser comparados, pois apresentam população, formas de administração da dieta e de análise metabólica, diferentes.

\section{- Gomas e mucilagens}

As gomas e mucilagens são exsudatos formados nos caules das plantas, com elevada concentração de polissacarídeos; são compostos hidrofílicos (Food and Nutrition Board, 2001) não digeríveis, solúveis em água e produzem gel em solução aquosa (Wursch, Xavier, Sunyer, 1997).

O estudo de Frias e Sgarbieri (1998), demonstrou o efeito da goma-guar na diminuição dos níveis de lipídios séricos e na manutenção dos níveis de glicose em ratos Wistar. Os autores demonstraram que ratos alimentados por 60 dias com goma-guar (10 e 20\%) apresentaram diminuição significativa $(\mathrm{p}<0,005)$ nos valores séricos de colesterol e triacilgliceróis, diminuição da ingestão calórica e do ganho de peso corporal e decréscimo na glicemia plasmática durante o primeiro mês de tratamento (Frias, Sgarbieri, 1998).
Um estudo recente, randomizado, controlado, duplo cego de três dias, conduzido com 60 adultos portadores de Diabetes Mellitus tipo 2 usando hipoglicemiante oral, avaliou o efeito pós prandial de uma barra de cereal enriquecida com a fibra solúvel guar. As barras testadas tinham a mesma quantidade de calorias e se diferenciavam na quantidade de goma guar: enquanto que a barra-teste continha $8,4 \mathrm{~g}$ de fibra, as barras-controle apresentam 0 ou $<5 \mathrm{~g}$ por porção. Foi avaliada a resposta glicêmica pós prandial, assim como a resposta insulínica. Os resultados demonstraram uma menor área sob a curva $(p<0,0001)$ nos indivíduos que consumiram a barra enriquecida com fibras, apresentando menor resposta glicêmica e insulínica se comparados às barras comerciais com baixo teor de fibras (Flamammg et al., 2006).

\section{- Psyllium}

O psyllium é uma fibra mucilaginosa viscosa e hidrofílica, presente na casca da semente do Psyllium (Plantago ovata), com alta concentração de hemicelulose e que aumenta o volume fecal, diminuindo o tempo de trânsito intestinal (Anderson et al., 1999).

No sentido de avaliar a resposta a esta fibra, um estudo randomizado, duplo cego, controlado, avaliou a efetividade do psyllium em 56 indivíduos diabéticos tipo 2 e hipercolesterolêmicos, em comparação a placebo. Os integrantes do estudo passaram por uma dieta de estabilização e, depois de randomizados, receberam 5,1g de psyllium ou placebo durante 8 semanas, duas vezes ao dia, concomitantemente com sua dieta tradicional. Os resultados demonstraram o efeito benéfico, de estabilização, do psyllium sobre a glicemia diária e a glicemia pós prandial, e o colesterol LDL se apresentou $8,9 \%(p<0,05)$ mais baixo no grupo-teste, em comparação a placebo. Os autores concluíram que a adição de psyllium pode melhorar o controle glicêmico e lipídico em indivíduos portadores de diabetes e hipercolesterolemia (Anderson et al., 1999).

\section{- Beta-glucanas}

As glucanas são polissacarídeos lineares, não ramificados, compostos por unidades de beta-glucanas, unidas por ligações $(1 \rightarrow 3)$ e $(1 \rightarrow 4)$ cuja irregularidade molecular se reflete na sua propriedade de solubilidade em água. Fazem parte das paredes celulares dos grãos, com concentração aumentada na camada sub-aleuroma, endosperma amiláceo e camada aleuroma. As beta-glucanas resistentes a processos digestivos, formam soluções viscosas em contato com a água e são pseudoplásticas (Wood et al., 1994).

A alta viscosidade de alimentos ricos em beta- 
glucanas depende da sua solubilidade, concentração e do peso molecular. Em baixas concentrações, as soluções de beta-glucanas se comportam como uma solução newtoniana; entretanto, em concentração superior a $0,2 \%$, as moléculas formam um emaranhado viscoso e pseudoplástico, conferindo as propriedades físico-químicas da fibra. $\mathrm{O}$ processamento do alimento pode afetar propriedades como a solubilidade, contribuindo para a diminuição da viscosidade de alimentos ricos em beta-glucanas (Antilla, Sontag-Strohm, Salovaara, 2004).

As beta-glucanas estão presentes em alta concentração na parede celular das células dos grãos de aveia (Avena sativa L.). O farelo de aveia é produzido a partir das camadas mais externas do grão de aveia (principalmente a camada aleuroma e sub-aleuroma), já a farinha, pobre neste tipo de fibra, é produzida após a moagem do flocos quando existe separação mecânica do farelo (De Sá, Francisco, Soares, 1998).

Em estudo cujo objetivo era avaliar a composição centesimal e o teor de beta-glucanas em cereais e derivados, Fujita e Figueroa (2003) demonstraram que os grãos de aveia e cevada são os que apresentam teor mais elevado de beta-glucanas. Nos produtos comerciais o maior teor de fibra se encontra no farelo de aveia que contém $9,68 \%$ de beta-glucanas, seguido dos flocos de aveia com 7,03\%. $\mathrm{O}$ estudo sugere que os teores de fibra podem variar com a safra e com fatores genéticos ligados ao grão (Fujita, Figueroa, 2003).

Este estudo corrobora o estudo de De Sá (1998), que avaliou a concentração de beta-glucanas no cultivar da aveia e produtos produzidos a partir desta, verificando se existia alteração no teor da fibra durante o seu processamento. Os resultados demonstraram teor mais elevado de beta-glucanas no farelo de aveia, com média de $9,5 \%$, contra $3,74 \%$ na farinha de aveia. O estudo conclui ainda que os tratamentos de estabilização, tostagem, corte e flocagem, que ocorrem na industrialização, não alteram o teor de beta-glucanas nos produtos finais (De Sá, Francisco, Soares, 1998).

Jenkins (1987) refere que a beta-glucana, sendo uma fibra solúvel, pode aumentar a viscosidade do bolo alimentar, tornando a digestão mais lenta, prejudicando a interação das enzimas pancreáticas com o substrato e diminuindo desta forma a taxa de digestão dos carboidratos pela amilase pancreática. A redução da taxa de absorção de carboidratos pelo trato digestório, limita o aumento da glicemia pós prandial. Esta limitação se dá pela presença de fibras que diminuem a digestão e absorção de carboidratos e pela fermentação bacteriana parcial, que ocorre no intestino grosso, produzindo metabólitos que afetam a ação da insulina (Jenkins et al., 1987). O mesmo autor, já referia que a utilização de 3 a 6 gramas de beta-glucana por dia (o equivalente a 40 gramas de farelo de aveia por dia) são suficientes para reduzir em até 5\% os níveis de LDL colesterol no plasma e reduzir os índices glicêmicos dos alimentos ingeridos (Jenkins et al., 1978). Este estudo foi de muita importância para a decisão da $F D A$, quando do reconhecimento desta fibra como alimento funcional e protetor da saúde (FDA, 1997).

Com o intuito de avaliar que fatores, além da diminuição da digestão e absorção de carboidratos, contribuem para o decréscimo da glicose pós prandial após a ingestão de beta- glucanas, Battilana et al. (2001) avaliaram 10 indivíduos saudáveis. Os indivíduos receberam por 2 dias uma dieta de estabilização, isoenergética, contendo a mesma quantidade de macronutrientes com presença ou não de $8,9 \mathrm{~g}$ de beta glucana ao dia. Ao terceiro dia, os indivíduos receberam uma refeição contendo ou não beta-glucana, a cada hora e por 9 horas seqüenciais, mimetizando a lenta taxa de absorção de carboidratos. Neste período foram avaliadas a concentração de insulina e a glicose pós prandial. Os resultados demonstraram que a taxa de insulina foi modestamente menor nos indivíduos que consumiram beta-glucana, nas últimas 3 das $9 \mathrm{~h}$ do estudo, devido ao decréscimo no aparecimento da glicose sistêmica. Não houve diferença significativa na redução da glicemia pós prandial e na taxa de insulina, nas 6 primeiras horas do estudo; porém, houve uma redução de $12 \%$ da glicose plasmática no grupo com beta-glucanas. Os resultados sugerem que a redução da glicemia pós-prandial observada em estudos prévios é, essencialmente, conseqüência dos efeitos das beta-glucanas sobre a taxa de absorção de carboidrato no trato digestório, e não um efeito dos produtos de fermentação do cólon (Battilana et al., 2001).

O estudo do grupo de Tappy, na Universidade de Lausanne, Suíça, demonstrou uma relação inversamente proporcional entre a quantidade de beta-glucanas na forma de cereais matinais e o pico de glicose plasmática. Foram avaliados dois diferentes tipos de café da manhã: um rico em fibras solúveis com três diferentes concentrações de beta glucanas $(4,0,6,0$ e 8,4 g), e outro denominado "continental" (pão, leite, presunto e queijo), pobre em fibras ( $0 \mathrm{~g}$ de beta glucanas). Os indivíduos submetidos ao desjejum contendo 4,0,6,0 e 8,4g de beta-glucanas tiveram valores de pico de glicemia $33 \%(\mathrm{p}<0,05), 58 \%$ $(p<0,001)$ e $62 \%(p<0,001)$ menores, respectivamente, quando comparados com o desjejum continental. As glicemias foram avaliadas pelo método da glicose oxidase, realizado através da coleta de sangue, em nível basal e em intervalos de 30 minutos, durante 4 horas após a ingestão do desjejum. O estudo concluiu que com $5 \mathrm{~g}$ de beta glucanas em desjejum contendo $35 \mathrm{~g}$ de carboidratos, 
diminui-se em $50 \%$ a resposta glicêmica pós prandial (Tappy, Gugloz,Wursch, 1996). Na mesma linha do estudo de Tappy, um estudo desenvolvido com indivíduos portadores de Diabetes Mellitus tipo 2 (DM2), randomizado e controlado, avaliou a resposta glicêmica pós-prandial a dois diferentes produtos a base de farelo de aveia, em comparação a uma carga de glicose de $12,5 \mathrm{~g}$. Os níveis de glicose plasmática foram inferiores nos tempos pósprandiais de 15, 30 e 45 minutos após a ingestão dos produtos com farelo de aveia. No mesmo estudo, uma carga de $25 \mathrm{~g}$ de glicose oral foi fornecida, com ou sem o acréscimo de $30 \mathrm{~g}$ de farelo de aveia. Após a ingestão da glicose acrescida do farelo de aveia, a média da glicemia pós prandial foi menor nos tempos pós prandiais de 30 , 45 e 60 minutos, em comparação à glicose oral. O estudo demonstrou um efeito positivo da beta-glucana na resposta glicêmica pós prandial, em indivíduos portadores de DM2 (Tapola et al., 2005).

O controle glicêmico próximo a níveis normais é o principal objetivo no tratamento do diabetes, portanto a intervenção nutricional é de fundamental importância. Sendo o carboidrato o maior determinante dos níveis glicêmicos pós prandiais, deve-se considerar o tipo e a quantidade do mesmo presente na dieta. A recomendação é de, no mínimo, $130 \mathrm{~g}$ de carboidratos/dia, de preferência os complexos, ricos em fibras. Baseado nos vários estudos que comprovam o impacto positivo das fibras solúveis na glicemia, um recente posicionamento da American Diabetes Association (2007) refere que um adequado nível de glicose sanguínea, próximo ao normal, é fundamental na prevenção das complicações crônicas do diabetes e do aparecimento do diabetes tipo 2, sendo este um dos principais objetivos no tratamento desta enfermidade. Indivíduos com alto risco de desenvolver diabetes tipo 2 e indivíduos portadores de diabetes tipo 1 devem ser encorajados a ingerir a recomendação de 14 gramas de fibra/1000 kcal em alimentos contendo grãos integrais (American Dietetic Association - ADA, 2007).

A hipoglicemia noturna é um problema freqüente em crianças portadoras de diabetes tipo 1 e estratégias terapêuticas para se evitar o risco de hipoglicemias noturnas severas, são benéficas a estes indivíduos. Um estudo (2000) realizado com 38 crianças, durante 12 noites consecutivas, avaliou a influência de um lanche noturno acrescido de beta-glucana, na forma de biscoitos e barras, comparado a um lanche convencional contendo iogurte. Os resultados demonstraram uma ligeira melhora na resposta glicêmica apenas até as 2 horas da manhã $(p<0,05)$, ou seja, 5 horas após o lanche, mas não houve diferença na prevalência de hipoglicemias noturnas, que foi de 27\% (Rami, Zidek, Schober, 2000).

Na seqüência de estudos com fibras, para investigar a resposta glicêmica pós prandial e a concentração de insulina, o grupo de Biorklund na Universidade de Lund, Suécia (2005), enriqueceu uma bebida com 5 e 10 gramas de beta glucana de aveia e cevada. Durante 3 semanas os indivíduos consumiram uma bebida controle e nas 5 semanas consecutivas 4 grupos receberam uma bebida contendo 5 ou 10 gramas de beta glucana e um grupo manteve a bebida controle. Comparada com a bebida controle, 5 gramas de beta-glucana da aveia diminuíram o colesterol total em 7,4\% $(p<0,01)$, a glicose em $19 \%$ ( $p=$ $0,005)$ e a insulina pós prandial em $33 \%(p=0,025)$ em um período de 30 minutos. A bebida contendo beta-glucana da cevada não demonstrou resultados significativos. Os autores concluem que 5 gramas de beta-glucana da aveia em bebidas, melhora o metabolismo da glicose e lipídios (Bjorklund et al., 2005).

Recentemente, um estudo de Granfeldt et al. avaliou o efeito da beta glucana presente em uma porção controlada de cereal, enriquecido com farelo de aveia. Trinta e dois indivíduos saudáveis receberam uma porção de cereal contendo 3 ou $4 \mathrm{~g}$ de beta glucana, que consumiram ao desjejum juntamente com pão branco, manteiga e queijo. A refeição referência foi a mesma que a teste, exceto pelo farelo de aveia que foi compensado por uma quantidade maior de pão. Os resultados demonstraram que não houve diferença significativa na glicemia e insulina pós prandial na refeição-teste contendo $3 \mathrm{~g}$ de beta glucana. Já a refeição-teste contendo $4 \mathrm{~g}$ de beta glucana apresentou uma resposta glicêmica significativamente menor $(p<0,05)$, se comparada à refeição padrão. As áreas sob a curva tanto para glicemia, quanto para insulina foram significativamente menores nas refeições-teste, se comparadas à refeição padrão $(p<0,05)$ (Granfeldt, Nyberg, Bjork, 2007).

Por ser menos palatável do que a aveia, são menos freqüentes os estudos que utilizam a beta-glucana da cevada. Um estudo da Universidade de Auckland, na Nova Zelândia, avaliou 18 indivíduos saudáveis entre 21 e 34 anos. Todos apresentavam perfil lipídico normal, glicose de jejum e pressão arterial normais. Os participantes foram randomizados para receber 4 tratamentos distintos, que foram comparados entre si. Os tratamentos eram: refeição controle rica em carboidratos; refeição rica em carboidrato + fibra; bebida controle rica em carboidratos e bebida rica em carboidrato + fibra. A suplementação de fibra continha 6,31 gramas de beta-glucana em 10gramas de cevada e foi acrescida à geléia que foi servida com pão branco ou em uma bebida isotônica adoçada com xarope de glicose. Foram coletadas amostras de sangue venoso durante um período pós prandial de 6 horas e foram analisados: glicose, insulina, HDL colesterol e LDL 
colesterol. Os resultados demonstraram resposta positiva para a glicose pós prandial apenas na refeição com fibra $(p<0,05)$, mas não na bebida acrescida da fibra $(p>0,05)$. A área sob a curva se apresentou $21 \%$ menor na refeição rica em carboidratos e acrescida de beta glucana, quando comparada à refeição controle sem a fibra. Houve também diminuição na área sobre sob a curva da insulina durante os 360 minutos da refeição-teste, quando comparada com a controle. Não houve diferença significativa no perfil lipídico, entre os tratamentos com e sem fibra. Os autores sugerem que não houve resposta positiva na bebida com fibra, provavelmente, por falta de tempo em se formar uma solução viscosa responsável pelo retardo do esvaziamento gástrico e diminuição da absorção de nutrientes (Poppitt et al., 2007).

\section{- Beta-glucana e índice glicêmico}

Jenkins et al. conceituaram índice glicêmico (IG) como um método pelo qual os alimentos podem ser classificados com base no impacto glicêmico, em relação à quantidade de carboidrato disponível no alimento (Jenkins et al., 1981). Os alimentos são classificados com base no seu potencial de aumentar a glicose sanguínea. De acordo com Sartorelli e Cardoso (2006), influenciam esta resposta glicêmica a natureza do amido, a presença de fibras alimentares e o teor de lipídeos e proteínas dos alimentos. $\mathrm{Na}$ dieta habitual, o índice glicêmico demonstra, através dos valores de glicose plasmática, a qualidade do carboidrato ingerido. A carga glicêmica é o produto entre índice glicêmico e quantidade de carboidrato (Jenkins et al., 2002). É uma medida de avaliação da quantidade e qualidade dos carboidratos ingeridos na dieta (Foster-Powell, Holt, Brand-Miller, 2002). Uma dieta com alimentos de baixo índice glicêmico têm como benefícios, a menor demanda de insulina, melhor manutenção da glicemia e redução da lipidemia, e fatores diretamente ligados à prevenção de doenças crônicas como a obesidade, diabetes e doenças cardíacas.

O consumo de fibras solúveis e alimentos de baixo índice glicêmico é o provável mecanismo que promove maior lentidão na digestão de nutrientes pelo trato digestório (Jenkins, Jenkins, 1995). Neste sentido, Jenkins et al. (2002) desenvolveram um estudo com o objetivo de determinar o efeito da adição de beta-glucana, na diminuição do índice glicêmico de produtos com base em aveia (Avena sativa $L$ ). Foram estudados 16 portadores de diabetes mellitus tipo 2 , os quais receberam $50 \mathrm{~g}$ de carboidrato na forma de pão branco, cereal matinal à base de aveia e 2 alimentos protótipo enriquecidos com beta-glucana.

Testes de glicemia capilar foram feitos em jejum e nos tempos pós prandiais 30 até $180 \mathrm{~min}$. Os protótipos ricos em fibra solúvel apresentaram índice glicêmico mais baixo, em torno de 4 unidades por grama de beta-glucana, em relação ao pão branco e cereal comercial; sugerindo esta fibra como um componente funcional para se controlar a glicemia pós-prandial.

Uma avaliação do Framingham Offspring Study demonstrou que dietas com baixo índice glicêmico estão associadas à diminuição do risco da síndrome da resistência à insulina (McKeown et al., 2004). Um trabalho de Cavallero et al. (2002) demonstra que a inclusão de $6 \mathrm{~g}$ de beta-glucana, diminui o índice glicêmico dos alimentos na média de 4 unidades por grama de beta-glucana, o que torna esta fibra um potencial adjuvante no tratamento do diabetes. Em estudo de 15 semanas com crianças obesas, houve diminuição do peso corporal nas crianças que receberam dieta de baixo índice glicêmico, quando comparadas com as que receberam dieta com gordura reduzida (Spieth et al., 2000). Em estudo de longa duração, foi demonstrado que os níveis de insulina em jejum foram reduzidos nos indivíduos tratados com dietas de baixo índice glicêmico (Slabber et al.,1994). No EURODIAB complications study (2001), 3000 adultos portadores de diabetes mellitus tipo 1 consumiram uma dieta com baixo índice glicêmico e apresentaram, independente da ingestão de carboidratos, gordura e fibras, uma menor medida da circunferência cintura quadril e circunferência da cintura (Toller et al., 2001). Baseado nas respostas científicas, um trabalho da Organização Mundial da Saúde publicado em 2003 sobre dieta, nutrição e doenças crônicas, considera possível o efeito preventivo de dietas com baixo índice glicêmico, enriquecidas com fibras, em relação à obesidade e ao diabetes (FAO/WHO, 2003).

\section{CONCLUSÃO}

As fibras estão presentes nos componentes da dieta ricos em carboidratos, são resistentes à digestão e absorção no intestino delgado e sofrem fermentação parcial no intestino grosso. São componentes principalmente de cereais e são classificadas em solúveis e insolúveis. As fibras insolúveis são responsáveis pela melhora do trânsito intestinal e as solúveis estão ligadas ao retardo do esvaziamento gástrico, redução do colesterol sérico e modulação da glicemia, por isso são importantes coadjuvantes na redução de risco e controle de doenças como a obesidade, doenças cardiovasculares e diabetes.

As beta-glucanas são fibras solúveis, presentes em quantidades elevadas no farelo de aveia e na cevada, que formam soluções viscosas e são pseudoplásticas. A beta-glucana promove aumento da viscosidade do bolo alimentar e retarda a absorção de nutrientes. A presença 
da beta glucana na dieta pode reduzir o pico glicêmico pós prandial e pode, de forma significativa, diminuir a quantidade de LDL colesterol no plasma sanguíneo.

Vários são os estudos para se determinar a influência da beta-glucana sobre a glicemia de portadores de diabetes mellitus, utilizando-se principalmente a aveia, a cevada ou enriquecendo alimentos com a fibra isolada. Os resultados apontam para um efeito positivo no controle da glicemia pós-prandial nas dietas contendo beta-glucana. Contudo, os estudos são heterogêneos e os resultados devem ser avaliados com cautela. Estudos utilizando ratos como modelo podem apresentar um resultado positivo que não necessariamente será reprodutível em humanos. A dieta fornecida juntamente com a fibra também é um fator limitante nos estudos, pois interfere no metabolismo, podendo mascarar o efeito da fibra. A maioria dos estudos utiliza ambientes e dietas altamente controlados o que não reflete verdadeiramente a resposta metabólica diária. Há necessidade de estudos em humanos no seu ambiente normal e consumindo sua dieta habitual, para que se tenha noção do quanto a fibra, incorporada a uma refeição completa, pode interferir na resposta glicêmica.

Indivíduos que apresentam doenças cardiovasculares, obesidade e diabetes podem se beneficiar com dietas ricas em cereais como a aveia e a cevada, os quais podem alterar positivamente o metabolismo de carboidratos e lipídios. Mais estudos são necessários nesta área, em indivíduos portadores de diabetes sob insulinoterapia intensiva e, de preferência, em ambientes não controlados.

\section{REFERÊNCIAS}

AMERICAN DIABETES ASSOCIATION. Nutrition Recommendations and Interventions for Diabetes: A position statement of the American Diabetes Association. Diabetes Care., v.30, p.48-65, 2007.

AMERICAN DIETETIC ASSOCIATION. Position of the American Dietetic Association : health implications of dietary fiber. J. Am. Diet. Assoc., v.102, p.993-1000, 2002.

ANDERSON, J.W.; ALLGOOD, L.D.; OELIGEN, J.A.; DAGGY, B.P. Effects of psyllium on glucose and serum lipid responses in men with type 2 diabetes and hypercholesterolemia. $\mathrm{Am}$. J. Clin. Nutr., v.70, p.466-473, 1999.

ANTILLA, H.; SONTAG-STROHM, T.; SALOVAARA, H. Viscosity of beta-glucan in oat products. J. Sci. Food Agric., v.13, p.80-87, 2004.
ARAÚJO, R.A.C.; ARAÚJO, W.M.C. Fibras alimentares. Rev. Bras. Nutr. Clin., v.13, p.201- 209, 1998.

BATTILANA, P.; ORNSTEIN, K.; MINEHIRA, K.; SCHWARZ, J.M.; ACHESON, K.; SCHNEITER, P.; TAPPY, L. Mechanisms of action of beta-glucan in postprandial glucose metabolism in health men. Eur. J. Clin. Nutr., v.55, p.327333, 2001.

BJORKLUND, M.; VAN REES, A.; MESINK, R.P.; ONNING, G. Changes in serum lipids and postprandial glucose and insulin concentrations after consumption of beverages with betaglucana from oats or barley: a randomized dose-controlled trial. Eur. J. Clin. Nutr., v.59, p.1272-1281, 2005.

BRENNAN, C.S. Dietary fiber, glycemic response, and diabetes. Mol. Nutr. Food Res., v.49, p.560-570,2005.

CAMERON-SMITH, D.; COLLIER, G.R.; O'DEA, K. Effect of soluble dietary fibre on the viscosity of gastrointestinal contents and the acute glycaemic response in the rat. $B r . J$. Nutr., v.71, p.563-571, 1994.

CATALANI, A.L.; KANG, E.M.S.; DIAS, M.C.G.; MACULEVICIUS, J. Fibras alimentares. Rev. Bras. Nutr. Clin., v.18, p.178-182, 2003.

CAVALLERO, A.; EMPILLI, S.; BRIGENTI, F.; STANCA, A.M. High $(1 \rightarrow 3,1 \rightarrow 4)$-beta-glucan barley fractions in bread making and their effects on human glycemic response. J. Cereal Sci., v.36, p. 59-66, 2002.

CHANDALIA, M. Dietary treatment of Diabetes Mellitus. New Engl. J. Med., v.342, p.1392-1398, 2000.

DAVIDSON, M.H.; MAKI, K.C.; KONG, J.C.; DUGAN, L.D.; TORRY, S.A.; HALL, H.A. Log term effects of consuming foods containing psyllium seed husk on serum lipids in subjects with hypercholesterolemia. Am. J. Clin. Nutr., v.67, p.367-376, 1998.

DE SÁ, R.M.; FRANCISCO, A.; SOARES, F.C.T. Concentração de beta-glucanas nas diferentes etapas do processamento da aveia. Ciênc. Tecnol. Aliment., v.18, p.425-427, 1998.

DERIVI, S.C.N.; MENDEZ, M.H.M.; FRANCISCONI, A.L.D.; SILVA, C.S.; CASTRO, A.M.; LUZ, D.P. Efeito hipoglicêmico das rações à base de berinjela em ratos. Ciênc. Tecnol. Aliment., v.22, p.164-169, 2002. 
ENDRESS, H.; FISHER, J. Fibers and fiber blends for individual needs: a physiological and technological approach. In: Advanced dietary fiber technology. Oxford: Blacwell Science, 2001. p.283-298.

FAO/WHO Report. Diet, nutrition and prevention of chronic diseases: report of a joint WHO/FAO expert consultation. Geneve, 2003. p.72-78 (WHO Technical Report Series 916).

FIETZ, V.; SALGADO, J.M. Efeito da pectina e da celulose nos níveis séricos de colesterol e triglicerídeos em ratos hiperlipidêmicos. Ciênc. Tecnol. Aliment., v.19, p. 318-321, 1999

FLAMMANG AN, KENDALL DM, BAUMGARTNER CJ, SLAGLE TD, CHOE YS. Effect of a viscous fiber bar on postprandial glycemia in subjects with type 2 diabetes. J. Am. Coll. Nutr., v.25, p.409-414, 2006;

FOOD AND NUTRITION BOARD. Dietary reference intakes: proposed definition of dietary fiber. Washington: National Academy Press, 2001. p.1-64.

FOSTER-POWELL, K.; HOLT, S.H.A.; BRAND-MILLER, J.C. International table of glycemic index and glycemic load values:2002. Am. J. Clin. Nutr., v.76, p.55-56, 2002.

FRIAS, A.C.D.; SGARBIERI, V.C. Guar Gum effect on food intake, blood serum lipids and glucose levels of Wistar rats. Plant Foods Hum. Nutr., v.53, p.15-28. 1998.

FUJITA, A.H., FIGUEROA, M.O.R. Composição centesimal e teor de beta-glucanas em cereais e derivados. Ciênc. Tecnol. Aliment., v.23, p.116-120, 2003.

GIACCO, R.; PARILLO, M.; RIVELLESE, A.A.; LASORELLA, G.; GIACCO, A.; DEPISCOPO, L.; RICCARDI, G. Long term dietary treatment with increased amounts of fiber rich low glicemic index natural foods improves blood glucose control and reduces the number of hypoglycemic events in type 1 diabetic patients. Diabetes Care, v.23, p.1461-1466, 2000

GRANFELDT, Y.; NYBERG, L.; BJÖRK, I. Muesli with 4g oat beta glucans lowers glucose and insulin responses after a bread meal in healthy subjects. Eur. J. Clin. Nutr., v.49, p.1-8, 2007.
HARBER, G.B. Depletion and disruption of dietary fiber. Effects on satiety, plasma glucose and serum insulin. Lancet, v.12, p.682-697, 1997.

JENKINS, D.J.; KENDALL, C.W.; VUKSAN, V.; VIDGEN, E.; PARKER, T.; FAULKNER, D.; MEHLING, C.C.; GARSETTI, M.; TESTOLIN, T.; CUNNANE, S.C.; RYAN, M.A.; COREY, P.N. Soluble fiber intake at a dose approved by the US Food and Drug Administration for a claim of health benefits: serum lipid risk factors for cardiovascular disease assessed in a randomized controlled crossover trial. Am. J. Clin. Nutr., v.75, p. 834-839, 2002.

JENKINS, D.J.A.; WOLEVER, T.M.S.; KALMUSKY, J.; GIUDICI, S.; GIORDANO, C.; PATTEN, R. Low glycemic index in hyperlipidemia: use of traditional starchy foods. Am. J. Clin. Nutr., v.46, p. 66-71, 1987.

JENKINS, D.J.A.; WOLEVER, T.M.S.; LEEDS, A.R.; GASSUL, M.A.; HAISSMAN, P.; DILAWARY, J.B.; GOFF, D.V.; METZ, G.L.; ALBERTI, K.G. Dietary fibers, fiber analogues and glucose tolerance: importance of viscosity. B. Med. J., v.1, p.1392-1394, 1978.

JENKINS, D.J.; WOLEVER, T.M.; TAYLOR, R.H.; BARKER, H.M.; FIELDEN, H.; BALDWIN, J.M.; BOWLING, A.S.; NEWMAN, H.C.; JENKINS, A.L.; GOFF, D.V. Glycaemic index of foods: a physiological basis for carbohydrate exchange. Am. J. Clin. Nutr., v.34, p.362-366, 1981.

JENKINS, D.J.; KENDALL, C.W.C.; AUGUSTIN, L.S.A.; FRANCESCHI, S.; HAMIDI, M.A. Glycemic index: overview of implications in health and disease. Am. J. Clin. Nutr., v.76, p.266-273, 2002.

JENKINS, D.J., JENKINS, A.L. Nutrition Principles and diabetes: a role for lent carbohydrate? Diabetes Care, v.18, p. 1491-1498, 1995.

JENKINS, A.L.; JENKINS, D.J.; ZDRAVKOVIC, U.; WÜRSH, P.; VUKSAN, V. Depression of glycemic index by high levels of beta-glucan fiber in two functional foods tested in type 2 diabetes. Eur. J. Clin. Nutr., v.56, p.622-628, 2002.

JOHNSON, I.T.; SOUTHGATE, D.A.T. Effects of fiber and resistant starch on intestinal mobility and function. Dietary Fibre and Related Substances. London: Chapan \& Hall, 1994. p.39-65. 
KURASAWA, S.; HAAK, V.S.; MARLETT, J.A. Plant residue and bacteria as bases for increased stool weight accompanying consumption of higher dietary fiber diets. J. Am. Coll. Nutr., v.19, p.426-433, 2000.

MCKEOWN, N.M.; MEIGS, J.B.; LIU, S.; SALTZMAN, E.; WILSON, P.W.F.; JAQUES, P.F. Carbohydrate nutrition, insulin resistence, and the prevalence of the metabolic syndrome in the Framinham offspring cohort. Diabetes Care, v. 27, p.538-546, 2004.

POPPITT, S.D.; VAN DRUNEN, J.D.E.; MCGILL, A.T.; MULVEY, T.B.; LEAHY, F.E. Supplementation of a highcarbohydrate breakfast with barley beta-glucan improves postprandial glycaemic response for meals but not beverages. Asia Pac. J. Clin. Nutr., v.16, p.16-24, 2007.

RAMI, B.; ZIDEK, T.; SCHOBER, E. Influence of beta-glucan enriched bedtime snack on nocturnal blood glucose levels in diabetic children. J. Pediatr. Gastroenterol. Nutr., v.32, p.34-36, 2000.

ROLLS, B.J.; BELL, E.A.; CASTELLANOS, V.H.; CHOW, M.; PELKMAN, C.L.; THORWART, M.L. Energy density but not fat content of foods affected energy intake in lean and obese women. Am. J. Clin. Nutr., v.69, p.863-871, 1999.

SALMERON, J.; ASCHERIO, A.; RIMM, E.B.; COLDITZ, G.A.; WING, A.L.; WILLETT, W.C. Dietary fiber, glycemic load, and risk of NIDDM in men. Diabetes Care, v.20, p.545$550,1997$.

SARTORELLI, D.S.; CARDOSO, M. Associação entre carboidratos da dieta habitual e diabetes mellitus tipo 2: evidências epidemiológicas. Arq. Bras. Endocrinol. Metab., v.50, p.415-426, 2006.

SCHWAB, U.; LOUHERANTA, A.; TORRONEN, A.; UUSITUPA, M. Impact of sugar beet pectin and polidextrose on fasting and postprandial glycemia and fasting concentrations of serum total and lipoprotein lipids in middle-aged subjects with abnormal glucose metabolism. Eur. J. Clin. Nutr., v.69, p.1073-1080, 2006.

SCHWARTZ, S.E.; LEVINE, R.A.; WEINSTOCK, R.S.; PETOKAS, S.; MILLS, C.A.; THOMAS, F.D. Sustained pectin ingestion: effect on gastric emptying and glucose tolerance in non-insulin-dependent diabetic patients. Am. J. Clin. Nutr., v.48, p.1413-1417, 1988.
SPIETH, L.E.; HARNISH, J.D; LENDERS, C.M.; RAEZER, L.B.; PEREIRA, M.A.; HANGEN, S.J. A low-glycemic index in the treatment of pediatric obesity. Arch. Pediatr. Adolesc. Med., v.154, p.947-951, 2000.

SLABBER, M.; BARNARD, H.C.; KUYL, J.M. DANNHAUSER, A.; SCHALL, R. Effects of a low insulin-response, energy restrict diet on weight loss and plasma insulin concentrations in hyperinsulinemic obese females. Am. J. Clin. Nutr., v.60, p.48-53, 1994.

STARK, A.; MAYERS, G.L. National Cholesterol education program recommendations for measurement triglyceride: Executive Summary. Clin. Chem., v.41, p.1421-1426, 1995.

TAPOLA, N.; KARVONEN, H.; NISKANEN, L.; MIKOLA, M.; SARKKINEN, E. Glycemic responses of oat bran products in type 2 diabetic patients. Nutr. Met. Card. Dis., v.15, p.255261, 2005.

TAPPY, L.; GUGOLZ, E.; WURSH, P. Effects of breakfast cereals containing various amounts of beta-glucan fibers on plasma glucose and insulin response in NIDDM subjects. Diabetes Care, v.19, p.831-834, 1996.

TOLLER, M.; BUYKEN, A.E.; HEITHKAMP, G.; CATHELINEAU, G.; FERRISS, B.; MICHEL, G.; GROUP EICS. Nutrient intakes as predictors of body weight in European people with type 1 diabetes. Int. J. Obes., v.25, p.1815-1822, 2001.

US FOOD AND DRUG ADMINISTRATION. FDA final rule for federal labeling: health claims: oats and coronary heart disease. Fed. Regist., v.62, p.3584-3681, 1997.

US FOOD AND DRUG ADMINISTRATION. Health Claims: Soluble fiber from certain foods and risk of heart diseases. Code of Federal Regulations, v.21, p.101-181, 2001.

WOOD, P.J.; BRAATEN, J.T.; SCOTT, F.W.; RIEDEL, K.D.; WOLINETZ, M.S.; COLLINS, M.W. Effect of dose and modification of viscous properties of oat gum on plasma and insulin following an oral glucose load. Brit. J. Nutr., v.72, p.731-743, 1994.

WURSCH P, XAVIER F, SUNYER P. The role of viscous soluble fiber in metabolic control of diabetes: A review with special emphasis on cereal rich in beta-glucan. Diabetes Care, v.20, p.1774-1780, 1997.

Recebido para publicação em 20 de março de 2008. Aceito para publicação em 30 de julho de 2008 . 